Konstruktivisme : Jurnal Pendidikan dan Pembelajaran

Vol. 11, No. 02, Juli, 2019. e-ISSN: 2442-2355

FKIP, Universitas Islam Balitar

Website: http://ejournal.unisbablitar.ac.id/index.php/konstruktivisme/index

Email: konstruktivisme@unisbablitar.ac.id

\title{
ANALISIS PEMAHAMAN PENDIDIKAN SEKS PADA PESERTA DIDIK MELALUI PEMBELAJARAN AGAMA DAN OLAHRAGA DI SDK 143 BHAKTYARSA KECAMATAN ALOK TIMUR KABUPATEN SIKKA
}

\author{
Hermus Hero \\ Dosen Pendidikan Guru Sekolah Dasar, FKIP, Universitas Nusa Nipa, Indonesia \\ Email: herohermus@gmail.com
}

ABSTRAK :

Tujuan penelitian ini adalah untuk mengetahui cara guru mengajarkan materi pada mata pelajaran agama dan olahraga yang berkaitan dengan seksualitas. Jenis data yang digunakan dalam penelitian ini adalah data kualitatif. Data kualitatif yaitu data yang disajikan dalam bentuk kata-kata bukan dalam bentuk angka. Yang termasuk data kualitatif dalam penelitian ini yaitu gambaran umum tentang kegiatan belajar mengajar pada mata pelajaran agama dan olahraga yang berkaitan dengan pendidikan seks. Pendidikan seks diajarkan di SDK 143 Bhaktyarsa melalui pembelajaran agama dan olahraga dengan materi dalam muatan pembelajaran tersebut berkaitan dengan seksualitas. Pada saat mengajarkan materi baik pembelajaran agama maupun olahraga, guru menggunakan metode berupa gambar-gambar dan melakukan pendekatan dengan menggunakan bahasa yang sederhana agar peserta didik bisa lebih bisa memahami materi.

Kata kunci: Agama, olahraga, seks.

ABSTRACT :

This research aims at investigating teachers' methods in teaching religion and sport related to sexuality. Kind of data used in this study was qualitative data. Qualitative data is kind of data that is written in the form of words. Qualitative data in this study included overview of learning process of religion and sport subjects concerning sex education. Sex education is taught in SDK 143 Bhaktyarsa through learning process of religion and sport via learning materials containing of sexuality. When explaining either religion or sport materials, teachers adopted pictures and simple language to make students more understand the materials.

Keywords: religion, sport, sex 
Hermus Hero. 2019. Analisis Pemahaman Pendidikan Seks pada Peserta Didik melalui

Pembelajaran Agama dan Olahraga di SDK 143 Bhaktyarsa Kecamatan Alok Timur

Kabupaten Sikka. Konstruktivisme : Jurnal Pendidikan dan Pembelajaran,11 (2): 144-153

\section{PENDAHULUAN}

Pendidikan merupakan suatu proses, upaya serta usaha sadar dan terencana untuk mendewasakan dan memanusiakan manusia agar mencapai manusia yang aktif mengembangkan potensi dirinya untuk memiliki kekuatan spiritual keagamaan, pengendalian diri, kepribadian, akhlak mulia, serta keterampilan yang diperlukan dirinya, masyarakat, bangsa dan negara. Jadi pada pendidikan tidak hanya berhubungan dengan hal-hal yang berkaitan dengan aspek pengetahuan (kognitif), melainkan juga berkaitan dengan keterampilan (psikomotorik), dan sikap (afektif) yang biasanya terdapat pada pendidikan karakter, khususnya pada pendidikan sex (sex education).

Dewasa ini kekerasan dan penyimpangan seksual yang menimpa anak di bawah umur menjadi fokus perhatian. Kasus kekerasan dan penyimpangan seksual terhadap anak tentu saja tidak dapat terlepas dari sistem pendidikan di Indonesia. Kekerasan seksual pada anak merupakan pemaksaan ataupun ancaman seorang anak dalam aktivitas seksual. Fenomena kekerasan dan penyimpangan seksual yang menimpa anak-anak di lingkungan mereka sendiri disebabkan oleh beberapa faktor, salah satunya adalah kurangnya pendidikan seks pada anak dan masyarakat. Maraknya kasus kekerasan seksual terhadap perempuan dan anak dipicu karena masih rendahnya pemahaman sex education atau pendidikan seks yang disebabkan oleh pendidikan seks yang kurang memadai.

Pendidikan seks wajib diberikan pada anak sedini mungkin, tepatnya dimulai saat anak berusia 6-12 tahun. Pada usia ini anak sudah berada pada tingkat sekolah dasar dimana anak sudah bisa melakukan komunikasi dua arah dan dapat mengerti mengenai organ tubuh mereka dan dapat dilanjutkan pengenalan tubuh internal. Upaya pengajaran pendidikan seks telah dilakukan pada SDK 143 Bhaktyarsa melalui pembelajaran agama dan olahraga. Namun pada kenyataannya masih terdapat yaitu kurang memadainya pembelajaran pendidikan seks di sekolah tersebut. Pendidikan seks yang kurang memadai terlihat dari tingkahlaku beberapa peserta didik laki-laki yang kurang sopan terhadap peserta didik perempuan saat mengganti kostum pada jam olahraga di UKS (Unit Kesehatan Siswa). Selain itu, beberapa peserta didik pun masih terlihat melontarkan kata-kata kasar terhadap lawan jenis. Sikap seperti ini merupakan hal yang kurang baik yang sudah mengarah pada kecenderungan sikap tidak etis yang mengarah pada kecenderungan seksual.

\section{METODE Jenis Penelitian}

Penelitian ini adalah untuk mengetahui pemahaman konsep tentang pendidikan seks pada peserta didik sekolah dasar di SDK 143 Bhaktyarsa Maumere. Sebagai upaya untuk memperoleh kebenaran atau mencari jawaban dari permasalahan yang ada, maka peneliti menggunakan jenis 
Hermus Hero. 2019. Analisis Pemahaman Pendidikan Seks pada Peserta Didik melalui Pembelajaran Agama dan Olahraga di SDK 143 Bhaktyarsa Kecamatan Alok Timur Kabupaten Sikka. Konstruktivisme : Jurnal Pendidikan dan Pembelajaran,11 (2): 144-153

penelitian kualitatif, karena penelitian ini menggunakan studi lapangan. Cara memperoleh data melalui berbagai instrumen yaitu observasi, wawancara, dan dokumentasi.

\section{Data dan Sumber Data}

Jenis data yang digunakan dalam penelitian ini adalah data kualitatif. Data kualitatif yaitu data yang disajikan dalam bentuk kata-kata bukan dalam bentuk angka. Yang termasuk data kualitatif dalam penelitian ini yaitu gambaran umum tentang kegiatan belajar mengajar pada mata pelajaran agama dan olahraga yang berkaitan dengan pendidikan seks.

Adapun sebagai sumber data dalam penelitian meliputi sumber data primer adalah guru kelas, guru agama, guru olahraga, peserta didik di SDK 143 Bhaktyarsa Maumere dan sumber data sekunder adalah foto dokumentasi kegiatan pembelajaran Olahraga dan Agama di SDK 143 Bhaktyarsa Maumere, serta studi literatur yang berkaitan dengan penelitian.

\section{Teknik Pengumpulan Data}

Pengumpulan data dilakukan pada natural setting (kondisi yang alamiah), sumber data primer, dan teknik pengumpulan data lebih banyak pada observasi berperan serta (participantobservation), wawancara mendalam (in depth interview) dan dokumentasi. (Sugiyono, 2017)

\section{Teknik Analisis Data}

\section{Analisis Data Kualitatif}

Peneliti menggunakan analisis selama di lapangan model Miles dan Huberman yang terdiri dari tiga tahap yaitu reduksi data, penyajian data, dan penarikan kesimpulan (Sugiyono, 2017). Analisis data sebelum di lapangan pada penelitian ini dimulai dari peneliti melakukan observasi untuk menemukan masalah yang terdapat di SDK 143 Bhaktyarsa, kemudian peneliti menganalisis masalah di SDK 143 Bhaktyarsa, kemudian peneliti memfokuskan penelitian kepada konsep pendidikan seks di SD pada pembelajaran agama dan olahraga di SDK 143 Bhaktyarsa.

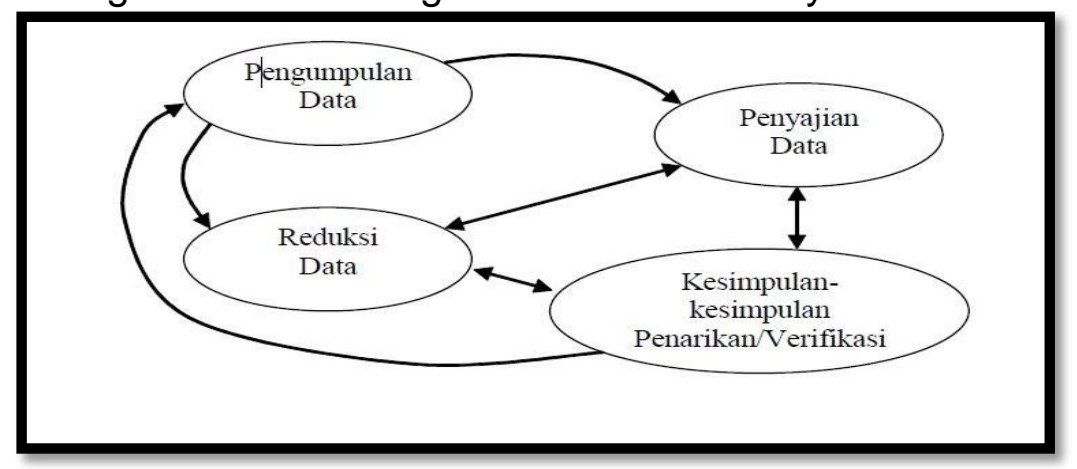

Gambar 1. Analisis data model Miles dan Huberman 
Hermus Hero. 2019. Analisis Pemahaman Pendidikan Seks pada Peserta Didik melalui

Pembelajaran Agama dan Olahraga di SDK 143 Bhaktyarsa Kecamatan Alok Timur

Kabupaten Sikka. Konstruktivisme : Jurnal Pendidikan dan Pembelajaran,11 (2): 144-153

\section{Analisis Data Kuantitatif}

Teknik analisis data yang digunakan dalam penelitian ini adalah analisis deskriptif menggunakan persentase. Rumus untuk mencari presentase dikuti dari Anas Sudijoni dalam Sundari (2016:38) untuk menghitung frekuensi relatif (presentase) sebagai berikut:

$$
\begin{gathered}
\qquad \boldsymbol{P}=\frac{\boldsymbol{f}}{\mathbf{N}} \times \mathbf{1 0 0} \\
\text { Keterangan : } \\
\mathrm{P}=\text { Angka Presentase } \\
f=\text { Jumlah Frekuensi Jawaban } \\
N=\text { Jumlah Subjek (Responden) }
\end{gathered}
$$

\section{HASIL DAN PEMBAHASAN}

Peneliti ini melakukan wawancara kepada kepala sekolah dan guru untuk mengetahui bagaimana persepsi guru tentang pendidikan seks, pentingnya pendidikan seks, pelaksanaan pendidikan seks di sekolah, dukungan sekolah terhadap pendidikan seks, sampai pada pelaksanaan pendidikan seks melalui pembelajaran agama dan olahraga yang dipaparkan malaui deskripsi berikut ini:

\section{Persepsi Tentang Pendidikan Seks di Sekolah Dasar}

Berdasarkan hasil wawancara dengan responden, peneliti menemukan bahwa pendidikan seks baik dan perlu diberikan sejak anak usia dini atau saat anak berada pada tingkat sekolah dasar. Pendidikan seks bukan hal yang tabu dan rahasia lagi. Seperti yang diungkapkan oleh Ibu Alexa Silvia sebagai wali kelas VA kepada peneliti saat diwawancarai pada Rabu 8 Mei 2019 sebagai berikut,

"Menurut saya pendidikan seks baik diberikan pada anak sejak dini dengan harapan supaya mereka lebih mempersiapkan diri agar kedepannya mereka lebih siap. kalau dulu orang tua merasa pendidikan seks ini tabu atau rahasia, tetapi sekarang ada manfaat positifnya."

\section{Pentingnya Pendidikan Seks}

Pendidikan seks merupakan hal yang sangat penting agar bisa mempersiapkan siswa untuk menyikapi hal-hal negatif yang akan terjadi. Seperti yang dikatakan oleh Bapak Edi saat diwawancarai pada Senin 13 Mei 2019,

"Saya kira untuk pendidikan seks di SD perlu untuk memberikan pengetahuan kepada siswa dan juga menjauhkan siswa dari hal-hal yang tidak baik."

Pernyataan yang sama juga disampaikan oleh lbu Alexa Silvia saat pada Rabu 8 Mei 2019 yakni, 
Hermus Hero. 2019. Analisis Pemahaman Pendidikan Seks pada Peserta Didik melalui

Pembelajaran Agama dan Olahraga di SDK 143 Bhaktyarsa Kecamatan Alok Timur

Kabupaten Sikka. Konstruktivisme : Jurnal Pendidikan dan Pembelajaran,11 (2): 144-153

"Pendidikan seks sangat perlu diadakan sejak usia SD karena sangat penting supaya anak bisa menjaga diri atau mawas diri."

\section{Pelaksanaan Pendidikan seks di Sekolah}

Pendidikan seks di SDK 143 Bhaktyarsa belum diajarkan secara khusus, tetapi masih melalui muatan pembelajaran. Seperti yang dikatakan oleh Ibu Alexa saat diwawancarai oleh peneliti pada tanggal 8 Mei 2019,

"Sejauh ini kalau secara khusus belum, hanya melaui pembelajaran IPA, itu dikelas $V$, dan agama di kelas $V$ tentang pertumbuhan fisik manusia."

\section{Dukungan Sekolah terhadap Pendidikan Seks}

Semua lembaga sekolah pasti sangat mendukung agar sekolah tersebut bisa menjadi lebih baik. Seperti halnya pendidikan seks, SDK 143 Bhaktyarsa sangat mendukung untuk hal tersebut. Seperti yang disampaikan oleh Suster Yuliana Nina saat diwawancarai oleh peneliti pada Senin, 20 Mei 2019,

"Sejauh ini sekolah sangat mendukung, tetapi belum terpikirkan sampai ke mengundang ahli atau pakar tentang pendidikan seks untuk datang, tetapi tidak menutup kemungkinan untuk mengundang ahli, dan terbuka untuk siapa saja yang mau datang untuk memberikan pemahaman pendidikan tentang seks."

\section{Pelaksanaan Pendidikan Seks melalui Pembelajaran Agama dan Olahraga}

Di SDK 143 Bhaktyarsa, pendidikan seks diajarkan melalui muatan pembelajaran termasuk pembelajaran agama dan olahraga. Seperti yang disampaikan oleh Ibu Alexa saat diwawancarai pada Rabu 8 Mei 2019,

"Pembelajaran agama tentang pendidikan seks setahu saya ada di kelas $V$, waktu itu guru agama mengajarkan tentang pertumbuhan fisik manusia. Kemudian kalau pembelajaran olahraga saya kurang tahu. Mungkin lebih jelasnya dapat ditanyakan pada guru mata pelajaran olahraga."

\section{Pendidikan Seks melalui Pembelajaran Agama}

Pendidikan seks yang diajarkan melalui pembelajaran agama yaitu melaui materi-materi yang terkait dengan pendidikan seks. Seperti halnya yang disampaikan oleh lbu Floriana selaku guru mata pembelajaran agama ketika diwawancarai pada Senin 13 Mei 2019,

"Pembelajaran agama ini membahas tentang ciptaan, bagaimana Allah menciptakan manusia kemudian diteruskan dengan manusia bertumbuh dan berkembang biak yang menjelaskan tentang persatuan antara pria dan wanita, orang tua dan hadirlah kita jadi anak-anak juga tahu tentang mengapa sampai terjadi pembuahan. Materi pembelajaran agama yang berkaitan dengan pendidikan seks terdapat di kelas $V$ dan VI. Di kelas $V$ tentang Allah menciptakan manusia, perbedaan antara pria dan wanita, jenis kelamin kemudian pertumbuhan fisik. Sedangkan di kelas VI tentang hidup murni atau hidup suci." 
Hermus Hero. 2019. Analisis Pemahaman Pendidikan Seks pada Peserta Didik melalui

Pembelajaran Agama dan Olahraga di SDK 143 Bhaktyarsa Kecamatan Alok Timur

Kabupaten Sikka. Konstruktivisme : Jurnal Pendidikan dan Pembelajaran,11 (2): 144-153

\section{Pendidikan Seks melalui Pembelajaran Olahraga}

Pendidikan seks yang diajarkan melalui pembelajaran olahraga yaitu melaui materi-materi yang terkait dengan pendidikan seks. Seperti halnya yang disampaikan oleh Bapak Edi selaku guru mata pelajaran olahraga ketika diwawancarai pada Senin, 13 Mei 2019,

"Pada pembelajaran olahraga juga bisa sebagai sarana pendidikan seks karena materi olahraga ada juga yang berkaitan dengan pendidikan seks. Materi yang berkaitan itu adalah tentang bagian-bagian tubuh, khususnya pada cara menjaga dan merawat organ tubuh"

Pemahaman Peserta Didik terhadap Materi Pembelajaran Agama dan Olahraga yang Diajarkan yang Berkaitan dengan Seksualitas

Tabel 1. Deskripsi Data Hasil Penelitian

\begin{tabular}{lllll}
\hline Data & Min. & Max & Mean & Std. Deviasi \\
\hline Pembelajaran Agama & 22 & 30 & 28,41 & 1,90 \\
Pembelajaran Olahraga & 7 & 10 & 9,41 & 0,93 \\
$\begin{array}{l}\text { Pemahaman Peserta } \\
\text { Didik }\end{array}$ & 35 & 40 & 38,11 & 1,45 \\
\hline
\end{tabular}

\section{Pembelajaran Agama}

Analisis deskriptif pada aspek pembelajaran agama dengan jumlah item pertanyaan sebanyak 15 butir diperoleh nilai maximum sebesar 30 dan minimum sebesar 15. Hasil dari penelitian diperoleh nilai maximum sebesar 30 dan nilai minimum sebesar 22. Skor data aspek pembelajaran agama tersebut diperoleh nilai mean (rerata) sebesar 28,41 dan standar deviasi sebesar 1,90 .

Tabel 2. Kategorisasi Data Aspek Pembelajaran Agama

\begin{tabular}{cccc}
\hline Interval & Frekuensi & $\begin{array}{c}\text { Presentasi } \\
(\%)\end{array}$ & Kategori \\
\hline $20-30$ & 1 & 3,7 & Kurang \\
$31-40$ & 26 & 96,3 & Baik \\
Total & 27 & 100,0 & \\
\hline
\end{tabular}

Berdasarkan tabel 2 diketahui sebanyak 1 siswa (3,7\%) mempunyai tingkat memahami pembelajaran agama dengan kategori kurang dan sebanyak 26 siswa $(96,3 \%)$ mempunyai tingkat memahami pembelajaran agama dengan kategori baik. Berdasarkan tabel di atas dapat disimpulkan bahwa tingkat pemahaman peserta didik pada aspek pembelajaran agama termasuk dalam kategori baik 
Hermus Hero. 2019. Analisis Pemahaman Pendidikan Seks pada Peserta Didik melalui

Pembelajaran Agama dan Olahraga di SDK 143 Bhaktyarsa Kecamatan Alok Timur

Kabupaten Sikka. Konstruktivisme : Jurnal Pendidikan dan Pembelajaran,11 (2): 144-153

\section{Pembelajaran Olahraga}

Analisis deskriptif pada aspek pembelajaran olahraga dengan jumlah item pertanyaan sebanyak 5 butir diperoleh nilai maximum sebesar 10 dan minimum sebesar 5. Hasil dari penelitian diperoleh nilai maximum sebesar 10 dan nilai minimum sebesar 7 . Skor data aspek pembelajaran agama tersebut diperoleh nilai mean (rerata) sebesar 9,41 dan standar deviasi sebesar 1,93.

Tabel 3 Kategorisasi Data Aspek Pembelajaran Olahraga

\begin{tabular}{cccc}
\hline Interval & Frekuensi & $\begin{array}{c}\text { Presentasi } \\
(\%)\end{array}$ & Kategori \\
\hline $5-7$ & 2 & 7,4 & Kurang \\
$8-10$ & 25 & 92,6 & Baik \\
Total & 27 & 100,0 & \\
\hline
\end{tabular}

\section{Pemahaman Peserta Didik}

Analisis deskriptif pada aspek pembelajaran agama dengan jumlah item pertanyaan sebanyak 20 butir diperoleh nilai maximum sebesar 40 dan minimum sebesar 20. Hasil dari penelitian diperoleh nilai maximum sebesar 40 dan nilai minimum sebesar 35 . Skor data aspek pembelajaran agama tersebut diperoleh nilai mean (rerata) sebesar 38,11 dan standar deviasi sebesar 1,45. Pada penelitian ini aspek pemahaman peserta didik dijabarkan menjadi 20 butir pertanyaan. Nilai minimum dan maximum digunakan sebagai dasar pengkategorian data. Hasil pengkategorian data aspek pemahaman peserta didik dapat dilihat pada tabel berikut:

Tabel 4. Kategorisasi Data Aspek Pemahaman Peserta Didik

\begin{tabular}{cccc}
\hline Interval & Frekuensi & $\begin{array}{c}\text { Presentasi } \\
(\%)\end{array}$ & Kategori \\
\hline $20-30$ & 0 & 0 & Kurang \\
$31-40$ & 27 & 100,0 & Baik \\
Total & 27 & 100,0 & \\
\hline
\end{tabular}

Berdasarkan tabel 4 diketahui sebanyak 0 siswa $(0 \%)$ mempunyai tingkat pemahaman dengan kategori kurang dan sebanyak 27 siswa (100\%) mempunyai tingkat pemahaman dengan kategori baik. Berdasarkan tabel di atas dapat disimpulkan bahwa tingkat pemahaman peserta didik pada aspek pemahaman peserta didik termasuk dalam kategori baik. 
Hermus Hero. 2019. Analisis Pemahaman Pendidikan Seks pada Peserta Didik melalui

Pembelajaran Agama dan Olahraga di SDK 143 Bhaktyarsa Kecamatan Alok Timur

Kabupaten Sikka. Konstruktivisme : Jurnal Pendidikan dan Pembelajaran,11 (2): 144-153

\section{Cara Guru Mengajarkan Materi pada Mata Pelajaran Agama dan Olahraga yang Berkaitan dengan Seksualitas}

Menurut Tretsakis (dalam Dewi, 2015) pendidikan seks menjelaskan tentang perilaku yang bersifat antonomis, behavior, emosi, kepribadian, pandangan hidup, lingkungan sosial, nilai-nilai moral yang berlaku dalam suatu masayarakat. Persepsi guru mengenai pentingnya pendidikan seks di sekolah dasar merupakan salah satu sumber yang melandasi pendidikan seks dan sangat penting untuk ditanamkan sejak usia dini yaitu usia sekolah dasar. Dengan memiliki bekal tentang pendidikan seks sejak dini akan memperkokoh pengetahuan peserta didik agar tidak terpengaruh oleh hal-hal yang tidak baik. Hal tersebut sesuai dengan pendapat yang diungkapkan oleh Kirkendall (dalam Andayani, 2016) tujuan pemberian pendidikan seks adalah Membantu anak atau remaja mempersiapkan perubahan-perubahan yang terjadi akibat pertumbuhannya (fisik), dengan membekali informasi tentang seks, kehamilan, dan melahirkan dalam bentuk yang benar dan sehat.

Persepsi guru tentang pentingnya pendidikan seks diajarkan sejak usia sekolah dasar agar peserta didik lebih mawas diri dalam menyikapi perkembangan zaman dan peserta didik bisa memahami tentang fungsi seksualnya yang baik digunakan pada waktunya serupa dengan pernyataan Wahyuningsih (2017) tujuan pendidikan seksual adalah: "Untuk membentuk suatu sikap emosional yang sehat terhadap masalah seksual dan membimbing anak dan remaja ke arah hidup dewasa yang sehat dan bertanggung jawab terhadap kehidupan seksualnya. Hal ini dimaksudkan agar mereka tidak menganggap seks itu suatu yang menjijikan dan kotor. Tetapi lebih sebagai bawaan manusia, yang merupakan anugrah Tuhan dan berfungsi penting untuk kelanggengan kehidupan manusia, dan supaya anakanak itu bisa belajar menghargai kemampuan seksualnya dan hanya menyalurkan dorongan tersebut untuk tujuan tertentu (yang baik) dan pada waktu yang tertentu saja."

Pendidikan seks diajarkan di sekolah melalui muatan pembelajaran, dimana terdapat materi yang berkaitan dengan pendidikan seks. Pembelajaran agama menjadi salah satu muatan pembelajaran yang menjadi sarana dalam mengajarkan pendidikan seks. Menurut persepsi guru tentang pendidikan seks melalui pendidikan seks melalui pembelajaran agama sangat penting karena pembelajaran agama ini membahas tentang ciptaan, bagaimana Allah menciptakan manusia kemudian diteruskan dengan manusia bertumbuh dan berkembang biak yang menjelaskan tentang persatuan antara pria dan wanita, orang tua dan hadirlah kita. Selain pembelajaran agama, pembelajaran olahraga juga menjadi sarana dalam mengajarkan pendidikan seks. Persepsi guru mengenai hal ini yaitu bahwa pada pembelajaran olahraga juga bisa sebagai sarana pendidikan seks karena materi olahraga ada juga yang berkaitan dengan pendidikan seks seperti Materi yang 
Hermus Hero. 2019. Analisis Pemahaman Pendidikan Seks pada Peserta Didik melalui

Pembelajaran Agama dan Olahraga di SDK 143 Bhaktyarsa Kecamatan Alok Timur

Kabupaten Sikka. Konstruktivisme : Jurnal Pendidikan dan Pembelajaran,11 (2): 144-153

berkaitan itu adalah tentang bagian-bagian tubuh, khususnya pada cara menjaga dan merawat organ tubuh. Pada saat mengajarkan materi, guru mempunyai metode yang digunakan untuk menyampaikan materi. Pada pembelajaran agama biasanya guru menggunakan gambar-gambar dan melakukan pendekatan dengan menggunakan bahasa yang sederhana agar peserta didik bisa lebih memahami materi.

\section{Pemahaman Peserta Didik terhadap Materi Pembelajaran Agama dan Olahraga yang Berkaitan dengan Seksualitas}

Hasil analisis deskriptif kuantitatif menunjukan bahwa tingkat pemahaman peserta didik kelas VA terhadap materi pendidikan seks melalui pembelajaran agama dan olahraga termasuk dalam kategori baik sebesar $100 \%$. Hasil ini menunjukan bahwa pemahaman peserta didik kelas VA terhadap materi pendidikan seks melalui pembelajaran agama dan olahraga baik.

Hasil berdasarkan aspek pembelajaran agama menunjukan bahwa tingkat pemahaman peserta didik terhadap pendidikan seks termasuk dalam kategori baik sebesar 96,3\%. dan kurang sebesar 3,7\%. Dari hasil tesebut menunjukan bahwa tingkat pemahaman siswa terhadap pendidikan seks dilihat dari aspek pembelajaran agama termasuk dalam kategori baik. Selain itu pada aspek pembelajaran olahraga menunjukan bahwa tingkat pemahaman pendidikan seks termasuk dalam kategori baik sebesar 92,6\% dan kurang sebesar 7,4\%. Dari hasil tersebut menunjukan bahwa tingkat pemahaman peserta didik terhadap pendidikan dilihat dari aspek pembelajaran olahraga termasuk dalam kategori baik.

\section{KESIMPULAN}

Pendidikan seks diajarkan di SDK 143 Bhaktyarsa melalui pembelajaran agama dan olahraga dengan materi dalam muatan pembelajaran tersebut berkaitan dengan seksualitas. Pada saat mengajarkan materi baik pembelajaran agama maupun olahraga, guru menggunakan metode berupa gambar-gambar dan melakukan pendekatan dengan menggunakan bahasa yang sederhana agar peserta didik bisa lebih bisa memahami materi.

Tingkat pemahaman peserta didik kelas VA di SDK 143 Bhaktyarsa termasuk dalam kategori baik sebesar 100\% yang menunjukan bahwa pemahaman peserta didik kelas VA terhadap materi pendidikan seks melalui pembelajaran agama dan olahraga baik. 
Hermus Hero. 2019. Analisis Pemahaman Pendidikan Seks pada Peserta Didik melalui Pembelajaran Agama dan Olahraga di SDK 143 Bhaktyarsa Kecamatan Alok Timur Kabupaten Sikka. Konstruktivisme : Jurnal Pendidikan dan Pembelajaran,11 (2): 144-153

\section{DAFTAR RUJUKAN}

Sugiyono (2017). Metode penelitian kuantitatif dan kualitatif $R$ \& $D$. BANDUNG: CV Alfabeta.

Dewi, F. M. 2016. Pengaruh Pengetahuan Tentang Kesehatan Reproduksi Remaja Terhadap Tingkat Kesiapan Remaja Menghadapi Menarche. Universitas Airlangga.

Diana Dewi Wahyuningsih. 2017. Pendidikan Seksualitas Pada Remaja Melalui Media Pembelajaran. Prosiding SNBK (Seminar Nasional Bimbingan dan Konseling 